\title{
CARACTERÍSTICAS MORFOFISIOLÓGICAS DE BROTOS MICROPROPAGADOS DE AGAPANTHO SOB DIFERENTES INTENSIDADES LUMINOSAS E CONCENTRAÇÕES DE SACAROSE
}

\author{
MORPHOLOGICAL AND PHYSIOLOGICAL CHARACTERISTICS OF SHOOTS \\ MULTIPLICATED AGAPANTHUS SHOOTS IN DIFFERENTS LIGHT INTENSITY \\ AND SUCROSE CONCENTRATIONS
}

\author{
Luciana Alves FOGAÇA ${ }^{1}$ \\ Denilson DORTZBACH ${ }^{2}$ \\ Antonio Carlos ALVES ${ }^{3}$ \\ Enio Luiz PEDROTTI ${ }^{4}$.
}

\begin{abstract}
RESUMO
Agapanthus umbellatus var. minor é uma planta ornamental muito utilizada como forração em jardins, podendo ser usada como flor de corte. Sua propagação é tradicionalmente efetuada por meio da divisão de touceiras, o que limita sua propagação em massa, porém com o uso da micropropagação é possível ampliar o plantio com mudas de alta qualidade. No entanto, este processo induz a um grande número de mudanças anatômicas, morfológicas e fisiológicas que são determinantes na morfogênese, no crescimento e no desenvolvimento das plantas in vitro. O presente trabalho teve como objetivo estudar a morfologia e a fisiologia de brotos micropropagados de Agapanthus umbellatus var. minor. Foram utilizados explantes retirados de brotações obtidas in vitro e inoculados em meio MS com diferentes concentrações de sacarose $(0,0 ; 1,5 ; 3,0$ e $4,5 \%$ ) e duas intensidades luminosas $\left(70\right.$ e $\left.140 \mathrm{mM} \mathrm{m}^{-2} \mathrm{~s}^{-1}\right)$, em um total de oito tratamentos, em disposição fatorial $2 \times 4$, utilizando o delineamento experimental inteiramente casualizado. Os resultados obtidos aos 60 dias indicaram que as variações na intensidade luminosa e na concentração de sacarose, influenciaram no desenvolvimento e no crescimento dos brotos. A ausência de sacarose, mesmo no nível mais elevado de intensidade luminosa, não estimulou a fotossíntese dos brotos. Houve uma grande variação nos resultados obtidos, no entanto recomenda-se a concentração de $30 \mathrm{~g} \mathrm{~L}^{-1}$ de sacarose com $70 \mathrm{mM} \mathrm{m}^{-2} \mathrm{~s}^{-1}$ de luz para a fase de multiplicação de Agapantho, essa combinação proporcionou maior produção de brotações e concentrações de clorofilas $a, b$ e total.
\end{abstract}

Palavras-chave: plantas ornamentais; cultura de tecidos; clorofila; Agapanthus umbellatus var. minor.

\begin{abstract}
Agapanthus umbellatus var. minor is an ornamental plant a lot used as lip in gardens, its can used as cut flower. Your propagation is traditionally made the dividing the roots, what limits your propagation in large scale, with use of the micropropagation it is possible to enlarge the planting with seedlings of high quality. However, this process induces a great number of changes anatomical, morphologic and physiologic that they are decisive in the morphogenesis, in the growth and in the development of the plants in vitro. This work aimed at studying the morphological and physiological traits of shoots of Agapanthus umbellatus var. minor multiplicated. It's used explants shift of the shoots obtained in vitro and inoculated in medium MS with concentrations sucrose differents $\left(0,0 ; 1,5 ; 3,0\right.$ e 4,5\%) and two light intensity $\left(70\right.$ e $\left.140 \mathrm{mM} \mathrm{m}^{-2} \mathrm{~s}^{-1}\right)$, totalyzing eight treatments, in factorial $4 \times 2$, the design utilized was completely randomized. The results indicated that the environment conditions, mainly light and sucrose concentration of the culture medium, influenced the development and the growth of shoots. It was observed that the absence of sucrose, even in the highest level light intensity, didn't at estimulate the photossyntesis the shoots. There was variation in results obtained; however advice the concentration of $30 \mathrm{~g} \mathrm{~L}^{-1}$ of sucrose and $70 \mathrm{mM} \mathrm{m}^{-2} \mathrm{~s}^{-1}$ of light for phase of multiplication of Agapantho, this combination has proposed the larger production of shoots and concentration of chlorophyll $a, b$ and total.
\end{abstract}

Key-words: ornamentals plants; tissue culture; chlorophyll; Agapanthus umbellatus var. minor.

${ }^{1}$ Engenheira Agrônoma, Doutoranda em Agronomia, UFPR. Programa de Pós Graduação em Agronomia, Produção Vegetal, Rua dos Funcionários, 1540, 80035-050, Curitiba - PR, E-mail: lufogaca@pop.com.br. Autor para correspondência.

²Engenheiro Agrônomo, Pesquisador da Epagri, Florianópolis. Email: agrofloripa@hotmail.com.

${ }^{3}$ Engenheiro Agrônomo, Prof. Dr. do Departamento de Fitotecnia do Centro de Ciências Agrárias, UFSC. E-mail: alves@cca.ufsc.br.

${ }^{4}$ Engenheiro Agrônomo, Prof. Dr. do Departamento de Fitotecnia do Centro de Ciências Agrárias, UFSC. E-mail: pedrotti@cca.ufsc.br. 


\section{INTRODUÇÃO}

O mercado nacional de plantas ornamentais tem apresentado um aumento crescente, tanto no montante financeiro movimentado, quanto no volume de plantas comercializadas. De acordo com JUNQUEIRA e PEETZ (2007), em 2006 o Brasil fechou o ano com exportações de flores e plantas ornamentais por um valor de US\$29,63 milhões, com um crescimento de $15,06 \%$ em relação ao ano anterior. Tendo em vista o aumento na demanda por flores e plantas ornamentais, a micropropagação tem sido empregada para a produção, em larga escala, de plantas sadias.

Uma espécie que vem apresentando grande destaque nas plantas utilizadas para jardim é Agapanthus umbellatus var. minor também conhecida como Agapantho ou Lírio do Nilo, é uma angiosperma da família Amaryllidaceae, pertencente à ordem Liliales (BOTANY, 2003). Essa espécie é muito utilizada como forração, podendo ser cultivada em bordaduras ao longo de canteiros, pois é uma planta que exige pouca manutenção. Além disso, suas flores podem ser utilizadas para corte devido a sua grande durabilidade (LORENZI e SOUZA, 1995).

Tradicionalmente, o Agapantho é propagado vegetativamente através da divisão de touceira. No entanto, esta técnica apresenta uma série de desvantagens, visto que a taxa de propagação é baixa, cerca de dez mudas por planta ao ano (LORENZI e SOUZA, 1995), além de possibilitar a dispersão de pragas e doenças que poderão ocorrer no viveiro de produção. A micropropagação pode ser uma ferramenta promissora para a propagação desta espécie, pois é possível ampliar o plantio de mudas de alta qualidade, pela produção de plantas livres de patógenos (GRATAPAGLIA e MACHADO, 1998).

O processo de micropropagação induz a um grande número de mudanças anatômicas, morfológicas e fisiológicas que muitas vezes tem limitado o cultivo in vitro de algumas espécies (DESJARDINS, 1995; GRATTAPAGLIA e MACHADO, 1998; LOURO e SANTIAGO, 2000). A heterogeneidade de respostas das mudas durante a micropropagação é promovida não só por fatores inerentes ao explante (genéticos e fisiológicos), mas também por modificações do ambiente in vitro. Estas modificações são determinantes na morfogênese, no crescimento e no desenvolvimento de plântulas in vitro (SHACKEL et al., 1990; GEORGE, 1996), interferindo no número de folhas, no teor de clorofila, na densidade estomática (PREECE e SUTTER, 1991; LIAN et al., 2002) e na fotossíntese, determinando a taxa de sobrevivência das mudas na fase de aclimatização (DESJARDINS et al., 1995; SINHA et al., 2002).

Um dos principais fatores que causam grande influência na fotossíntese de plântulas cultivadas in vitro é a luz (GALZY e COMPAN, 1992). A quantidade e a qualidade da luz, bem como o fotoperíodo, podem afetar o crescimento e o desenvolvimento de plântulas in vivo (SMITH, 1982) e in vitro (ECONOMOU e READ, 1987; VLAHOS et al., 1992; GEORGE, 1996). Esta influência se deve ao grande impacto sobre o acúmulo de pigmentos, formação de clorofila, diferenciação de cloroplastos e anatomia da folha (DESJARDINS et al., 1995).
Outro fator que pode determinar um papel importante no controle da atividade fotossintética de plântulas in vitro é a adição de carboidratos ao meio de cultura, pois o crescimento da maioria das culturas in vitro é sustentado pela sacarose ou por outros açúcares (PREECE e SUTTER, 1991). Estes podem ser utilizados pelas plântulas quando a taxa de fotossíntese não permite assegurar um balanço positivo em carbono, definindo assim uma nutrição mixotrófica (GALZY e COMPAN, 1992).

Com base na hipótese de que a concentração de sacarose no meio de cultura e a intensidade luminosa influenciam no tipo de crescimento morfofisiológico dos brotos micropropagados, o presente trabalho teve como objetivo estudar aspectos morfológicos e fisiológicos do crescimento e desenvolvimento de brotos de Agapanthus umbellatus var. minor multiplicados in vitro.

\section{METODOLOGIA}

Este trabalho foi realizado no Laboratório de Morfogênese e Bioquímica Vegetal, localizado no Centro de Ciências Agrárias da Universidade Federal de Santa Catarina, em Florianópolis-SC.

Foram utilizados brotos de Agapanthus umbellatus var. minor obtidos do terceiro subcultivo sucessivo em meio geleificado MS (MURASHIGE e SKOOG, 1962) com 17,8 ?M de BAP (6Benzilaminopurina). Após serem individualizados e padronizados, tendo sua altura entre 2,5 e $3,0 \mathrm{~cm}$, os brotos foram transferidos para frascos com capacidade de $300 \mathrm{~mL}$ contendo $50 \mathrm{~mL}$ do mesmo meio utilizado durante os subcultivos e diferentes concentrações de sacarose $(0,0 ; 1,5 ; 3,0$ e $4,5 \%)$. Como agente geleificante foi utilizado ágar (Vetec) $0,6 \%$ e o $\mathrm{pH}$ foi ajustado com $\mathrm{NaOH}\left(1 \mathrm{~mol} \mathrm{~L}^{-1}\right) \mathrm{em}$ 5,9 , antes da autoclavagem (durante $15 \mathrm{~min}$, sob $121^{\circ} \mathrm{C}$ e $1,5 \mathrm{~atm}$ de pressão).

Após a inoculação, os explantes foram mantidos em sala de crescimento com fotoperíodo de $16 \mathrm{~h}$ e temperatura média de $22^{\circ} \mathrm{C}$ com variação de ? $2{ }^{\circ} \mathrm{C}$, por um período de 60 dias. Os tratamentos dispostos em um fatorial $4 \times 2$, com quatro concentrações de sacarose no meio de cultura e duas intensidades luminosas (70 e $140 \mathrm{~mol} \mathrm{~m}^{-2} \mathrm{~s}^{-1}$ ), providas por lâmpadas brancas fluorescentes (PHILIPS - TLT $40 \mathrm{~W}$ ), em um total de oito tratamentos, em delineamento inteiramente casualizado. Cada tratamento foi composto por três repetições, contendo dez frascos por parcela com cinco brotos cada, totalizando 50 brotos por repetição.

Após 60 dias de cultivo, foram avaliadas as seguintes características dos explantes: número e altura de brotos $(\mathrm{cm})$, número de folhas por broto, massas fresca e seca $(\mathrm{g})$ de parte aérea, utilizandose amostras de 25 brotos por repetição escolhidos ao acaso.

Os 25 brotos restantes foram utilizados para a determinação do conteúdo de clorofila " $a$, b e total", da densidade estomática e das características biométricas dos estômatos.

A determinação do conteúdo de clorofila " $a$, be total" consistiu na coleta de amostras de $100 \mathrm{mg}$ de 
massa fresca da parte aérea. As amostras foram incubadas com 7,0 mL de DMSO (dimetilsulfóxido) sem trituração, por 30 min a $65^{\circ} \mathrm{C}$. Após filtração, seu volume foi completado para $10 \mathrm{~mL}$ com DMSO. Desses extratos, $2 \mathrm{~mL}$ foram analisados em espectrofotômetro (UV - visível, SHIMADZU), para os valores de absorbância entre 645 e $663 \mathrm{~nm}$. Os valores obtidos foram submetidos à fórmula de ARNON (1949), conforme descrito por HISCOX e ISRAELSTAM (1979). A clorofila total foi a soma da "Chl a e Chl b", e para sua determinação, foram utilizadas 25 amostras.

A determinação da densidade estomática (número de estômatos por $\mathrm{mm}^{2}$ de superfície foliar) e das dimensões das células-guarda (comprimento: eixo longitudinal entre os dois pólos da célula e largura: eixo transversal na porção média da célula) foram realizadas nas amostras das quais se extraiu a clorofila. Após a extração da clorofila, as folhas foram cortadas, sendo somente a parte mediana da folha $(1,0 \mathrm{~cm})$ usada para análise. Estas, em seguida foram fixadas sobre lâminas histológicas com a ajuda de uma lamínula e de algumas gotas de água esterilizada. A observação da epiderme foi realizada na face adaxial e abaxial, com o auxílio de um microscópio ótico (OLYMPUS $\mathrm{CH} 30$, ocular WH10
$X$ 22), com um aumento de 400 vezes e com uma área conhecida de $0,24 \mathrm{~mm}^{2}$. Tanto para a densidade estomática quanto para a dimensão das célulasguardas, em cada lâmina, foram feitas leituras em cinco campos. Em cada campo foram medidos cinco estômatos, totalizando 25 estômatos medidos por lâmina.

Os dados obtidos foram avaliados por meio da análise de variância (ANOVA) em delineamento experimental inteiramente casualizado. Os dados do número de brotações e da densidade estomática foram transformados em ? $\mathrm{x}+1$ para a análise. As médias dos tratamentos foram comparadas pelo teste de Duncan a $5 \%$ de probabilidade, conforme recomendações de STEEL e TORRIE (1980).

\section{RESULTADOS E DISCUSSÃO}

O número e altura dos brotos (Tabela 1) e o número de folhas por broto (Tabela 2), durante a fase de multiplicação de Agapantho, não apresentaram interação entre os fatores sacarose e intensidade luminosa, havendo, portanto o efeito isolado dos fatores.

TABELA 1 - Número e altura de brotos de Agapanthus umbellatus var. minor multiplicados em meio MS $+17,8$ $\mathrm{mM}$ de BAP com diferentes concentrações de sacarose e mantidas em duas intensidades luminosas, no período de 60 dias. UFSC, Florianópolis - SC, 2004.

\begin{tabular}{|c|c|c|c|c|c|c|}
\hline \multirow[b]{3}{*}{$\begin{array}{l}\text { Concentração } \\
\text { Sacarose }\left(\mathrm{g} \mathrm{L}^{-1}\right)\end{array}$} & \multicolumn{3}{|c|}{ Número de brotações } & \multicolumn{3}{|c|}{ Altura de brotações (cm) } \\
\hline & \multicolumn{6}{|c|}{ Intensidade Luminosa $\left(? \mathrm{~mol} \mathrm{~m}^{-2} \mathrm{~s}^{-1}\right)$} \\
\hline & 70 & 140 & Média & 70 & 140 & Média \\
\hline 0 & 0,00 & 0,00 & $0,00 \mathrm{~d}$ & 0,00 & 0,00 & $0,00 \mathrm{~d}$ \\
\hline 15 & 3,52 & 2,69 & $3,10 \mathrm{c}$ & 3,88 & 2,93 & $3,41 \mathrm{a}$ \\
\hline 30 & 5,36 & 4,75 & $5,05 \mathrm{a}$ & 3,12 & 2,02 & $2,57 \mathrm{c}$ \\
\hline 45 & 6,25 & 3,42 & $4,75 \mathrm{~b}$ & 3,09 & 2,37 & $2,73 \mathrm{~b}$ \\
\hline Média & $3,35 \mathrm{~A}$ & $2,44 \mathrm{~B}$ & & $2,52 \mathrm{~A}$ & $1,83 \mathrm{~B}$ & \\
\hline CV (\%) & & 10,41 & & & 18,46 & \\
\hline
\end{tabular}

Médias seguidas pela mesma letra, minúscula nas colunas e maiúscula nas linhas, não diferem significativamente pelo teste de Duncan, a $5 \%$ de probabilidade.

TABELA 2 - Número de folhas por broto de Agapanthus umbellatus var. minor multiplicados em meio MS + 17,8 $\mathrm{mM}$ de BAP com diferentes concentrações de sacarose e mantidas em duas intensidades luminosas, no período de 60 dias. UFSC, Florianópolis - SC, 2004.

\begin{tabular}{|c|c|c|c|}
\hline \multirow[b]{2}{*}{$\begin{array}{c}\text { Concentração Sacarose } \\
\qquad\left(\mathrm{g} \mathrm{L}^{-1}\right)\end{array}$} & \multicolumn{3}{|c|}{ Intensidade Luminosa $\left(? \mathrm{~mol} \mathrm{~m}^{-2} \mathrm{~s}^{-1}\right)$} \\
\hline & 70 & 140 & Média \\
\hline 0 & 0,00 & 0,00 & $0,00 \mathrm{~d}$ \\
\hline $\begin{array}{l}15 \\
30\end{array}$ & $\begin{array}{l}5,87 \\
5,86\end{array}$ & $\begin{array}{l}4,78 \\
4,62\end{array}$ & $\begin{array}{l}5,32 b \\
5,22 c c\end{array}$ \\
\hline 45 & 5,53 & 5,79 & 5,66 a \\
\hline Média & $3,83 \mathrm{~A}$ & $3,39 \mathrm{~B}$ & \\
\hline CV (\%) & & 6,14 & \\
\hline
\end{tabular}

Médias seguidas pela mesma letra, minúscula nas colunas e maiúscula nas linhas, não diferem significativamente pelo teste de Duncan, a $5 \%$ de probabilidade.

O maior número de brotos por explante foi obtido com $30 \mathrm{~g} \mathrm{~L}^{-1}$ de sacarose e $70 \mathrm{mmol} \mathrm{m}^{-2} \mathrm{~s}^{-1}$ de intensidade luminosa (Tabela 1). A ausência de sacarose no meio de cultura provocou um estado estacionário no crescimento e no desenvolvimento dos brotos, seguindo-se de necrose e morte das brotações após 30 dias de cultivo in vitro. Desse modo, verificou-se que a ausência de sacarose, mesmo no nível mais elevado de intensidade luminosa, não estimulou a fotossíntese in vitro dos 
brotos. Portanto, para a espécie em estudo, há necessidade de adição de uma fonte de carbono no meio de cultura para o seu desenvolvimento. Resultados semelhantes foram obtidos por FOGAÇA et al. (2006) na multiplicação de Agapantho em biorreator de imersão temporária, que após 20 dias de cultivo ocorreu a morte das brotações cultivadas em meio com ausência de sacarose. Por outro lado, a maior altura dos brotos ocorreu quando foi adicionado $15 \mathrm{~g} \mathrm{~L}^{-1}$ de sacarose e $70 \mathrm{mmol} \mathrm{m}^{-2} \mathrm{~s}^{-1}$ de intensidade luminosa (Tabela 1 ). No entanto, esta concentração de sacarose no meio de cultura proporcionou a formação de um menor número de brotações e também a formação de brotações frágeis (pouco desenvolvidas, com folhas estreitas).

A adição de $45 \mathrm{~g} \mathrm{~L}^{-1}$ de sacarose e $70 \mathrm{mmol}$ $\mathrm{m}^{-2} \mathrm{~s}^{-1}$ de intensidade luminosa apresentou maior incremento para o número de folhas por broto (Tabela 2). Por outro lado, o número de brotações por explante foi superior na concentração de $30 \mathrm{~g} \mathrm{~L}^{-1}$ de sacarose, enquanto que para a altura dos brotos os melhores resultados foram evidenciados com $15 \mathrm{~g}$ $\mathrm{L}^{-1}$ de sacarose. Durante a fase de multiplicação de Nephrolepis exaltata também foram obtidos resultados diferentes, de acordo com a concentração de sacarose (PASQUAL et al., 1994).

Brotações de Agapantho quando submetidas à maior intensidade luminosa, apresentaram redução no número e na altura dos brotos (Tabela 1) e no número de folhas por broto (Tabela 2), indicando possível fotoinibição. De acordo com TAIZ e ZEIGER (2004), quando as folhas são expostas a uma quantidade de luz maior do que podem utilizar, provavelmente o centro de reação do fotossistema II seja inativado e danificado. Segundo LEE et al. (1985), brotações de Liquidambar styraciflua cultivadas in vitro sob presença de alta intensidade luminosa $\left(314 \mathrm{mmol}^{-2} \mathrm{~s}^{-1}\right)$ mostraram comportamento semelhante. De acordo com esses autores, o dano causado, pela luz, nos pigmentos, acarretou numa menor saturação fotossintética, afetando o crescimento e o desenvolvimento de plantas in vitro das plantas.

Para a produção de massas fresca e seca dos brotos observou-se que houve interação significativa entre os fatores sacarose e luz (Tabela 3). A melhor produção de massas fresca e seca foi obtida na concentração $15 \mathrm{~g} \mathrm{~L}^{-1}$ de sacarose e 70

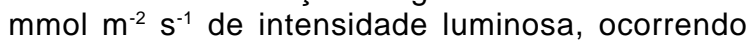
redução dessas características, nas demais concentrações. Contrastando com estes resultados, FILA et al. (1998), TICHÁ et al. (1998) e DESJARDINS et al. (1995) no cultivo in vitro de videira, fumo e morango, respectivamente, observaram que a produção de massa fresca in vitro destas espécies foi aumentada com a adição de sacarose. Apesar da menor concentração de sacarose apresentar melhor resultado para massas fresca e seca de brotos de Agapantho sugere-se a concentração de $30 \mathrm{~g} \mathrm{~L}^{-1} \mathrm{de}$ sacarose no meio de cultura, pois de acordo com GROUT e MILLAN (1985) a redução da sacarose durante a fase de multiplicação não pode ser um método adequado, visto que esta redução pode afetar o número de folhas formadas, estas que são consideradas como órgãos estoque de nutrientes que posteriormente afetarão a fase de aclimatização.

TABELA 3 - Massas fresca e seca de brotações de Agapanthus umbellatus var. minor multiplicados em meio MS + 17,8 mM de BAP com diferentes concentrações de sacarose e mantidas em duas intensidades luminosas, no período de 60 dias. UFSC, Florianópolis - SC, 2004.

\begin{tabular}{|c|c|c|c|c|}
\hline & \multicolumn{2}{|c|}{ Massa fresca $(\mathrm{g})$} & \multicolumn{2}{|c|}{ Massa seca $(g)$} \\
\hline & \multicolumn{4}{|c|}{ Intensidade Luminosa $\left(? \mathrm{~mol} \mathrm{~m}^{-2} \mathrm{~s}^{-1}\right)$} \\
\hline $\begin{array}{l}\text { Concentração } \\
\text { Sacarose }\left(\mathrm{g} \mathrm{L}^{-1}\right)\end{array}$ & 70 & 140 & 70 & 140 \\
\hline 0 & $0,00 \mathrm{dA}$ & $0,00 \mathrm{dA}$ & $0,00 \mathrm{dA}$ & $0,00 \mathrm{dA}$ \\
\hline 15 & 0,69 aA & $0,41 \mathrm{aB}$ & 0,070 aA & $0,040 \mathrm{aB}$ \\
\hline 30 & $0,48 \mathrm{cA}$ & $0,39 \mathrm{bB}$ & $0,049 \mathrm{cA}$ & $0,038 \mathrm{bB}$ \\
\hline 45 & $0,57 \mathrm{bA}$ & $0,37 \mathrm{cB}$ & $0,054 \mathrm{bA}$ & $0,036 \mathrm{cB}$ \\
\hline CV (\%) & & & & \\
\hline
\end{tabular}

Médias seguidas pela mesma letra, minúscula nas colunas e maiúscula nas linhas, não diferem significativamente pelo teste de Duncan, a $5 \%$ de probabilidade.

Ao analisar a concentração de clorofila em folhas de brotos de Agapantho, verificou-se que não houve interação significativa entre as concentrações de sacarose e as intensidades luminosas (Tabela 4). As maiores concentrações de clorofila $a, b$ e total foram obtidas nos brotos crescidos com $30 \mathrm{~g} \mathrm{~L}^{-1}$ de sacarose. POSPÍSILOVÁ et al. (1988) mostraram que a síntese de clorofila, em plântulas de tabaco e batata, foi beneficiada com a adição de até $2 \%$ de sacarose no meio de cultura. SERRET et al. (1995) também obtiveram maior produção de clorofila em plântulas de Gardênia com o aumento da concentração de sacarose em até $30 \mathrm{~g} \mathrm{~L}^{-1}$ no meio de cultura. Entretanto, há evidências de que o aumento desta fonte de carbono, no meio de cultura, pode acarretar no decréscimo das taxas de clorofila de algumas espécies e redução ou inibição da taxa fotossintética (ARIGITA et al., 2002), como foi observado no presente trabalho. 
TABELA 4 - Concentrações de clorofila $a, b$ e total em folhas de brotos de Agapanthus umbellatus var. minor multiplicados em meio $\mathrm{MS}+17,8 \mathrm{mM}$ de BAP por um período de 60 dias, submetidos a quatro concentrações de sacarose e dois níveis de intensidade luminosa. UFSC, Florianópolis - SC, 2004.

\begin{tabular}{|c|c|c|c|c|c|c|c|c|c|}
\hline \multirow{3}{*}{$\begin{array}{c} \\
\text { Concentração } \\
\text { Sacarose } \\
\left(\mathrm{g} \mathrm{L}^{-1}\right)\end{array}$} & \multicolumn{3}{|c|}{$\begin{array}{c}\text { Clorofila a } \\
\text { ( } \mathrm{mg} \mathrm{g}^{-1} \text { massa fresca) }\end{array}$} & \multicolumn{3}{|c|}{$\begin{array}{c}\text { Clorofila } b \\
\text { ( } \mathrm{mg} \mathrm{g}^{-1} \text { massa fresca) }\end{array}$} & \multicolumn{3}{|c|}{$\begin{array}{c}\text { Clorofila total } \\
\text { ( } \mathrm{mg} \mathrm{g}^{-1} \text { massa fresca) }\end{array}$} \\
\hline & \multicolumn{9}{|c|}{ Intensidade Luminosa (? $\left.\mathrm{mol} \mathrm{m}^{-2} \mathrm{~s}^{-1}\right)$} \\
\hline & 70 & 140 & Média & 70 & 140 & Média & 70 & 140 & Média \\
\hline 0 & 0,00 & 0,00 & $0,00 \mathrm{~d}$ & 0,00 & 0,00 & $0,00 \mathrm{~d}$ & 0,00 & 0,00 & $0,00 \mathrm{~d}$ \\
\hline 15 & 3,83 & 3,61 & $3,72 \mathrm{c}$ & 1,38 & 1,43 & $1,40 \mathrm{c}$ & 5,21 & 5,12 & $5,16 \mathrm{c}$ \\
\hline 30 & 4,83 & 4,65 & $4,74 \mathrm{a}$ & 1,87 & 1,80 & $1,84 \mathrm{a}$ & 6,71 & 6,46 & $6,59 a$ \\
\hline 45 & 4,34 & 3,65 & $4,00 \mathrm{~d}$ & 1,60 & 1,63 & $1,62 \mathrm{~b}$ & 5,95 & 5,29 & $5,62 \mathrm{~b}$ \\
\hline Média & $3,25 \mathrm{~A}$ & $2,97 \mathrm{~B}$ & & $1,21 \mathrm{~A}$ & $1,21 \mathrm{~A}$ & & $4,47 \mathrm{~A}$ & $4,22 \mathrm{~A}$ & \\
\hline CV (\%) & & 8,90 & & & $11,6 \varepsilon$ & & & 8,6 & \\
\hline
\end{tabular}

Médias seguidas pela mesma letra, minúscula nas colunas e maiúscula nas linhas, não diferem significativamente pelo teste de Duncan, a $5 \%$ de probabilidade.

Em relação à intensidade luminosa, somente a concentração de clorofila a apresentou diferença significativa com maior incremento na presença de $70 \mathrm{mmol} \mathrm{m}^{-2} \mathrm{~s}^{-1}$ (Tabela 4 ). Estes resultados corroboram com os obtidos por MOREIRA (2000), NUNES (2001) e VIÑA et al. (2001), os quais constataram que o aumento da intensidade luminosa acarretou redução na concentração de pigmentos nas folhas de brotações de videira, macieiras e abacateiro, respectivamente.

Provavelmente, estes resultados estejam relacionados à velocidade de decomposição da clorofila, pois segundo KRAMER e KOZLOWSKI (1979) a clorofila é constantemente sintetizada e destruída em presença de luz, mas sob intensidades luminosas elevadas, a velocidade de decomposição é maior, sendo o equilíbrio estabelecido em uma intensidade luminosa menor.
Em relação aos estômatos, através de observação microscópica, foi possível verificar que os brotos de Agapantho in vitro possuem folhas com característica anfiestomática, caracterizada pela presença de estômatos nas faces abaxial e adaxial. A ocorrência de estômatos em ambas as faces da epiderme tem sido considerada como um mecanismo adaptativo para maximizar a condutância de $\mathrm{CO}_{2}$, quando luz e água são fatores limitantes (KRAMER, 1969).

A maior densidade estomática (tanto na face adaxial como da abaxial) foi obtida na intensidade luminosa de $140 \mathrm{mmol} \mathrm{m}^{-2} \mathrm{~s}^{-1} \operatorname{com} 30 \mathrm{~g} \mathrm{~L}^{-1} \mathrm{de}$ sacarose (Tabela 5). Portanto, verifica-se que o aumento da intensidade luminosa promoveu o aumento da densidade estomática.

TABELA 5 - Densidade estômatica nas faces adaxial e abaxial de folhas de brotos de Agapanthus umbellatus var. minor multiplicados em meio MS $+17,8 \mathrm{mM}$ de BAP com diferentes concentrações de sacarose e mantidos em duas intensidades luminosas, por um período de 60 dias. UFSC, Florianópolis SC, 2004.

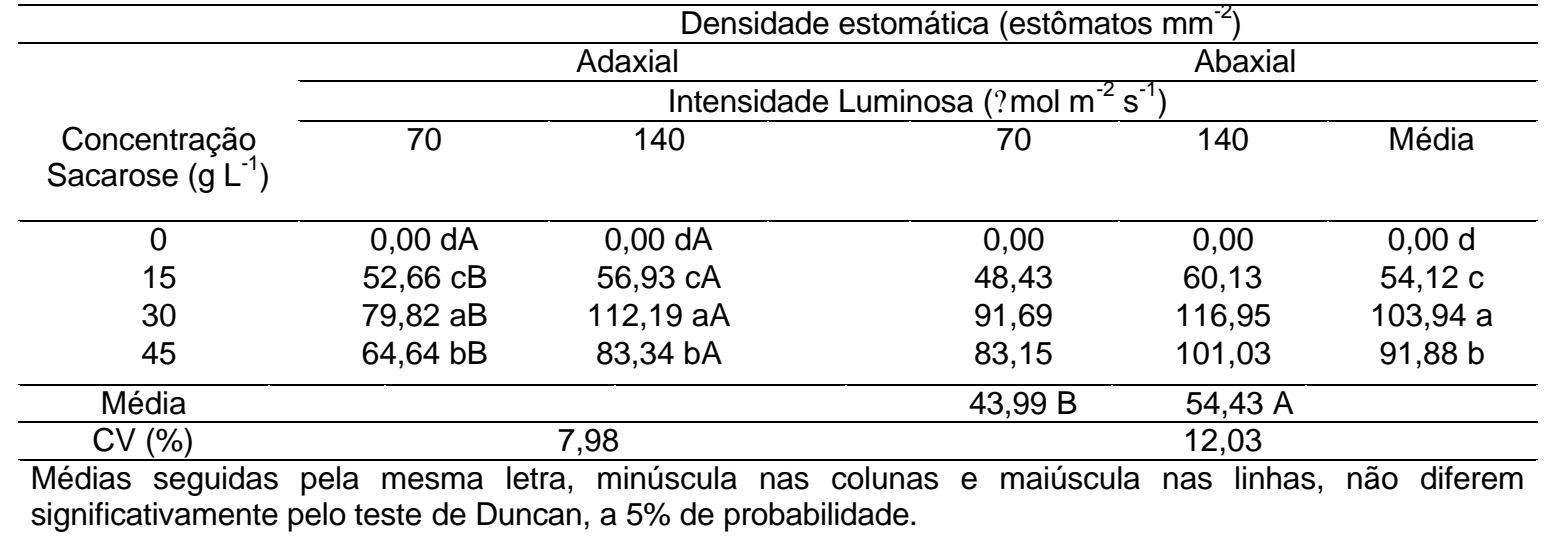

Além da diferença na densidade estomática nas duas faces foliares de Agapantho, os estômatos formados apresentaram também diferenças biométricas. O comprimento das células-guarda, de ambas as faces foliares apresentaram diferenças significativas somente para a concentração de sacarose adicionada ao meio de cultura (Tabela 6). $\mathrm{Na}$ face adaxial, o maior comprimento foi observado na concentração de $45 \mathrm{~g} \mathrm{~L}^{-1}$ e na face abaxial com $30 \mathrm{~g} \mathrm{~L}^{-1}$ de sacarose. 
TABELA 6 - Comprimento de células-guarda de estômatos nas faces adaxial e abaxial de folhas de brotos de Agapanthus umbellatus var. minor multiplicados em meio MS $+17,8 \mathrm{mM}$ de BAP com diferentes concentrações de sacarose e mantidos em duas intensidades luminosas, por um período de 60 dias. UFSC, Florianópolis - SC, 2004.

\begin{tabular}{|c|c|c|c|c|c|c|}
\hline \multirow[b]{4}{*}{$\begin{array}{l}\text { Concentração } \\
\text { Sacarose }\left(\mathrm{g} \mathrm{L}^{-1}\right)\end{array}$} & \multicolumn{6}{|c|}{ Comprimento das células-guarda (?m) } \\
\hline & \multicolumn{3}{|c|}{ Adaxial } & \multicolumn{3}{|c|}{ Abaxial } \\
\hline & \multicolumn{6}{|c|}{ Intensidade Luminosa (? $\left.\mathrm{mol} \mathrm{m}^{-2} \mathrm{~s}^{-1}\right)$} \\
\hline & 70 & 140 & Média & 70 & 140 & Média \\
\hline 0 & 0,00 & 0,00 & $0,00 \mathrm{~d}$ & 0,00 & 0,00 & $0,00 \mathrm{~d}$ \\
\hline 15 & 33,75 & 31,66 & $32,70 \mathrm{c}$ & 36,66 & 32,5 & $34,58 \mathrm{~b}$ \\
\hline 30 & 36,24 & 29,30 & $32,77 \mathrm{~b}$ & 34,85 & 35,41 & $35,13 \mathrm{a}$ \\
\hline 45 & 31,66 & 34,30 & $32,98 \mathrm{a}$ & 29,02 & 31,45 & $30,24 \mathrm{c}$ \\
\hline Média & $25,41 \mathrm{~A}$ & $23,81 \mathrm{~A}$ & & $25,13 \mathrm{~A}$ & $24,84 \mathrm{~A}$ & \\
\hline CV $(\%)$ & & 15,20 & & & 9,6 & \\
\hline
\end{tabular}

Médias seguidas pela mesma letra, minúscula nas colunas e maiúscula nas linhas, não diferem significativamente pelo teste de Duncan, a $5 \%$ de probabilidade.

A largura das células-guarda, de Agapantho apresentou um comportamento diferenciado. Na face adaxial observou-se interação entre luz e sacarose (Tabela 7). A maior largura das células-guarda foi obtida com $70 \mathrm{mmol} \mathrm{m}^{-2} \mathrm{~s}^{-1}$ de intensidade luminosa e $15 \mathrm{~g} \cdot \mathrm{L}^{-1}$ de sacarose. Sob a intensidade luminosa de $140 \mathrm{mmol} \mathrm{m}^{-2} \mathrm{~s}^{-1}$, a maior largura também ocorreu com $15 \mathrm{~g} \mathrm{~L}^{-1}$ de sacarose. Porém, foi inferior à obtida

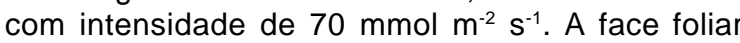
abaxial não apresentou interação entre os fatores sacarose e intensidade luminosa, havendo somente efeito da concentração de sacarose adicionada ao meio de cultura. Células-guarda mais largas foram obtidas na concentração $15 \mathrm{~g} \mathrm{~L}^{-1}$ de sacarose. $\mathrm{O}$ aumento de sacarose no meio de cultura, em ambas as faces foliares, promoveu a formação de estômatos com um formato menos alongado (Tabela 6) e em maior número (Tabela 5). Segundo ABRAMS et al. (1992), a redução do tamanho das células-guarda pode minimizar a perda excessiva de água pelas folhas. Por outro lado, esse resultado também pode promover uma diminuição na absorção de gás carbônico e consequentemente diminuição na taxa fotossintética, podendo influenciar negativamente 0 comportamento dos brotos durante a fase de aclimatização.

TABELA 7 - Largura de células-guarda de estômatos nas faces adaxial e abaxial de folhas de brotos de Agapanthus umbellatus var. minor multiplicados em meio MS $+17,8 \mathrm{mM}$ de BAP com diferentes concentrações de sacarose e mantidos em duas intensidades luminosas, por um período de 60 dias. UFSC, Florianópolis - SC, 2004.

\begin{tabular}{|c|c|c|c|c|c|}
\hline \multirow[b]{4}{*}{$\begin{array}{l}\text { Concentração } \\
\text { Sacarose }\left(\mathrm{g} \mathrm{L}^{-1}\right)\end{array}$} & \multicolumn{5}{|c|}{ Largura das células-guarda (?m) } \\
\hline & \multicolumn{3}{|c|}{ Adaxial } & \multicolumn{2}{|c|}{ Abaxial } \\
\hline & \multicolumn{5}{|c|}{ Intensidade Luminosa $\left(? \mathrm{~mol} \mathrm{~m}^{-2} \mathrm{~s}^{-1}\right)$} \\
\hline & 70 & 140 & 70 & 140 & Média \\
\hline 0 & $0,00 \mathrm{dA}$ & $0,00 \mathrm{dA}$ & 0,00 & 0,00 & $0,00 \mathrm{~d}$ \\
\hline 15 & $9,71 \mathrm{aA}$ & $6,52 \mathrm{aB}$ & 7,50 & 6,52 & $7,01 \mathrm{a}$ \\
\hline 30 & $5,41 \mathrm{cA}$ & $4,85 \mathrm{cB}$ & 6,11 & 5,69 & $5,90 \mathrm{~b}$ \\
\hline 45 & $5,83 \mathrm{bB}$ & $5,83 \mathrm{bA}$ & 5,13 & 5,76 & $5,44 \mathrm{c}$ \\
\hline Média & & & $4,68 \mathrm{~A}$ & $4,49 \mathrm{~A}$ & \\
\hline CV (\%) & & 19,77 & & 17,24 & \\
\hline
\end{tabular}

Médias seguidas pela mesma letra, minúscula nas colunas e maiúscula nas linhas, não diferem significativamente pelo teste de Duncan, a $5 \%$ de probabilidade.

\section{CONCLUSÃO}

Os brotos micropropagados de Agapantho apresentaram variação nas características morfofisiológicas, em função da intensidade luminosa e da concentração de sacarose. Por isso houve a necessidade de uma avaliação em conjunto das variáveis, para se determinar a combinação sacarose e intensidade luminosa mais adequada.
Dentre as combinações recomenda-se a concentração de $30 \mathrm{~g} \mathrm{~L}^{-1}$ de sacarose com 70 ?M $\mathrm{m}^{-2} \mathrm{~s}^{-1}$ de luz para a fase de multiplicação de Agapantho. Porém, sugerem-se mais estudos para verificar o efeito destas combinações sobre o desempenho de brotos na fase de aclimatização. 
1. ABRAMS, M.D.; KLOEPPEL, B.D., KUBISKE, M.E. Ecophysiological and morphological responses to shade and drought in two contrasting ecotypes of Prunus serotina. Tree Physiology, v. 10, p. 343-355, 1992.

2. ARIGITA, L.; GONZÁLEZ, A.; TAMÉS, R.S. Influence of $\mathrm{CO}_{2}$ and sucrose on photosynthesis and transpiration of Actinidia deliciosa explants cultured in vitro. Physiologia Plantarum, v. 115, n. 1, p. 166-173; 2002.

3. BOTANY. Disponível em: <http:www.botany.com> Acesso em 20 de nov. de 2003

4. DESJARDINS, Y. Overview of factors influencing photosynthesis of micropropagated plantlets and their effect on acclimatization. In: CARRE, F.; CHAGVARDIEFF, P (Eds) Ecophysiology and photosynthetic in vitro cultures. Aix en Provence: CEA, 1995. p. 145-160.

5. DESJARDINS, Y.; HDIDER, C.; DE RIEK, J. de. Carbon nutrition in vitro - regulation and manipulation of carbon assimilation in micropropagated systems. In: AITKEN-CHRISTIE, J.; KOZAI, T.; SMITH, M.A.L. (Eds.), Automation and environmental control in plant tissue culture. Dordrecht: Kluwer Academic Publishers, 1995. p. 441-471.

6. ECONOMOU, A.S.; READ, P.E. Light treatments to improve efficiency of in vitro propagation systems. HortiSciense, v. 22, n. 5, p. 751-754, 1987.

7. FILA, G.; GHASHGHAIE, J.; HOARAU, J.; CORNIC, G. Photosynthesis, leaf conductance and water relations of in vitro cultured grapevine rootstock in relation to acclimatisation. Physiologia Plantarum, v. 102, p. 411-418, 1998.

8. FOGAÇA, L.A.; DORTZBACH, D.; ALVES, A.C.; PEDROTTI, E.L. Características morfofisiológicas de brotações de Agapanthus umbellatus var. minor multiplicadas em biorreator de imersão temporária. Plant Cell Culture \& Micropropagation, v. 2, n. 2, p. 80-87, 2006.

9. GALZY, R.; COMPAN, D. Remarks on mixotrophic and autotrophic carbon nutrition of Vitis plantlets cultured in vitro. Plant Cell, Tissue and Organ Culture, v. 31, p. 239-244, 1992.

10. GEORGE, E.F. Plant propagation by tissue culture. 2 ed. London: Exergetics, 1996. v. 2. 1361 p.

11. GRATTAPAGLIA, D.; MACHADO, M.A. Micropropagação. In: TORRES, A.C.; CALDAS, L.S.; BUSO, J.A. Cultura de tecidos e transformação genética de plantas. Brasília: EMBRAPA-CNPH, 1998. p. 183-260.

12. GROUT, B.W.W.; MILLAN, S. Photosynthetic development of micropropagated strawberry plantlets following transplanting. Annals Botany, v. 55, p. 121-131, 1985.

13. HISCOX, J.D.; ISRAELSTAM, G.F. A method for the extration of chlorophyll from leaf tissue without maceration. Canadian Journal of Botanic, v. 57 , p. $1332-1334,1979$

14. JUNQUEIRA, A.H.; PEETZ, M.S. da. Las exportaciones brasileiras de flores y plantas crescen más del $124 \%$ entre 2001 y 2006. Horticultura Internacional, n. 56, p. 76-79, 2007.

15. KRAMER, P.J. Plant and soil water relationship: a modern synthesis. New York: Mc Graw Hill, 1969. 538 p.

16. KRAMER, T.; KOZLOWSKI, T. Physiology of woody plants. New York: Academic Press, 1979. $811 \mathrm{p}$.

17. LEE, N.; WETZSTEIN, H.Y.; SOMMER, H.E. Effects of quantum flux density on photosynthesis and chloroplast ultrastructure in tissue-cultured plantlets and seelings of Liquidambar styraciflua L. towards improved acclimatization and field survival. Plant Physiology, v. 78, p. 637-641, 1985.

18. LIAN, M.L.; MURTHY, H.N.; PAEK, K.Y. Culture method and photosynthetic photon flux affect photosynthesis, growth and survival of Limonium Misty Blue in vitro. Scientia Horticulturae, v. 95, p. 239-249, 2002.

19. LORENZI, H.; SOUZA, H.M. de; Plantas ornamentais no Brasil: arbustivas, herbáceas e trepadeiras. Nova Odessa: Editora Plantarum, 1995. 734 p.

20. LOURO, R.P.; SANTIAGO, L.J.M. Ultraestrutura de plantas cultivadas in vitro. Caderno de Pesquisa Série Botânica, v. 12 , n. 1 , p. 99-107, 2000.

21. MOREIRA, F.M. Avaliação morfo-fisiológica e bioquímica do porta-enxerto de videira Paulsen 1103 in vitro. Florianópolis, 2000. 91 f. Dissertação (Mestrado em Recursos Genéticos Vegetais) - Universidade Federal de Santa Catarina.

22. MURASHIGE, T.; SKOOG, F. A revised medium for rapid growth and bioassays with tobacco tissue cultures. Physiologia Plantarum, v. 15, p. 473-497, 1962.

23. NUNES, J.C. de O. Caracterização morfofisiológica de porta-enxertos de macieira (Malus spp) nos sistemas de cultura in vitro e ex vitro. Florianópolis; 2001. 92 f. Dissertação (Mestrado em Recursos Genéticos Vegetais) Universidade Federal de Santa Catarina.

24. PASQUAL, M.; HOSHIKA, E.; ISHIDA, J.S. Influência de diferentes concentrações de sacarose e sais minerais sobre a multiplicação in vitro de Nephrolopsis exaltata uma samambaia ornamental. Pesquisa Agropecuária Brasileira, v. 29, n. 11, p. 1681-1684, 1994.

25. POSPÍSILOVÁ, J.; SOLÁROVÁ, J.; CATSKÝ, J.; ONDREJ, M.; OPATRNÝ, Z. The photosynthetic characteristics during the micropropagation of tobacco and potato plants. Photosynthetica, v. 22, p. 205-213, 1988.

26. PREECE, J.E.; SUTTER, E.G. Acclimatization of micropropagated plants to the greenhouse and field. In: DEBERGH, P.C.; ZIMMERMAN, R.H. (Eds). Micropropagation: technology and application. Dordrecht: Kluwer Academic Publishers, 1991. p. 71-93.

27. SERRET, M.D.; TRILLAS, M.I.; ARAUS, J.L. The effect of sucrose and light levels on stable carbon isotope composition and photosynthetic pigments of gardenia leaflets in vitro. In: CARRE, F.; CHAGVARDIEFF, P. (Eds.). Ecophysiology and photosynthetic in vitro cultures. Cadarache: CEA, 1995. p. 169-172.

28. SHACKEL, K.A.; NOVELLO, V.; SUTTER, E.G. Stomatal function and cuticular conductance in whole tissue-cultured apple shoots. Journal of American Society for Horticultural Science, v. 115, n. 30, p. 468-472, 1990.

29. SMITH, H. Light quality, photoperception and plant strategy. Annual Review of Plant Physiology and Plant Molecular Biology, v. 33, p. 481-518, 1982.

30. SINHA, A.K.; HOFMANN, M.G.; RÖMER, U.; KÖCKENBERGER, W.L.; ELLING, L.; ROITSCH, T. Metabolizable and nonmetabolizable sugars activate different signal transduction pathways in tomato. Plant Physiology, v. 128, n. 4, p.14801489, 2002.

31. STEEL, R.G.D.; TORRIE, J.H. Principles and precedures of statistics: a biometrical approach. 2 ed. New York: MacGraw-Hill, 1980. 631 p.

32. TAIZ, L.; ZEIGER, E. Fisiologia vegetal. 3. ed. Porto Alegre: Artmed, 2004. 719 p. 
FOGAÇA, L.A. et al. Características morfofisiológicas de brotos...

33. TICHÁ, I.; CÁP, F.; PASCOVSKÁ, D.; HOFMAN, P.; HAISEL, D.; CAPKOVÁ, V.; SHAFER, C. Culture on sugar medium enhances photosynthetic capacity and high light resistance of plantlets grown in vitro. Physiologia Plantarum, v. 102, p. $155-162,1998$.

34. VLAHOS, J.C.; MARTAKIS, G.F.P.; HEUVELINK, E. Daylength, light quality, and temperature influence growth and development of Achimenes. HortScience, v. 27, p. 1269-1271, 1992.

35. VINÃ, G de la; BARCELÓ-MUÑOZ, A.; PLIEGO-ALFARO, F. Effect of culture media and irradiance level on growth and morphology of Persea americana Mill microcuttings. Plant Cell, Tissue and Organ Culture, v. 65, p. 229-237, 2001.

Recebido em 11/04/2007 Aceito em 13/09/2007 